\title{
Фазовый и гранулометрический состав, структурно-морфологические и текстурные характеристики композиционного сорбента
}

\author{
Везенцев А.И. ${ }^{1}$, Данг Минь Тхуи ${ }^{1,2}$, Перистая Л.Ф. ${ }^{1}$, Михайлюкова М.О. ${ }^{1}$ \\ ${ }^{1}$ Белгородский государственный начиональный исследовательский университет, Белгород \\ ${ }^{2}$ Российско-Вьетнамский тропический центр, Ханой, Вьетнам
}

Поступила в редакцию 20.03.2018 г.

DOI: https://doi.org/10.17308/sorpchrom.2018.18/532

В работе представлены результаты исследований фазового и гранулометрического состава, морфологических и текстурных характеристик композиционного сорбента на основе бентонитоподобной глины и гидроксилапатита, синтезированного методом химического осаждения. Методами рентгенофазового анализа, ИК-спектроскопии и сканирующей электронной микроскопии зафиксировано образование кристаллов гидроксилапатита в композиционном сорбенте, которые расположены на поверхности частиц минералов, слагающих бентонитоподобную глину. Методом лазерной дифракции определено, что в композиционном сорбенте преобладают частицы размером от 1.0 до 10 мкм. Их содержание достигает 74.76 масс.\%. Методом просвечивающей электронной микроскопии установлено, что кристаллы монтмориллонита имеют вид пленок размером $100-300$ нм, гидроксилапатита - удлиненную форму длиною от 35 до 65 нм и шириною от 12 до 20 нм, размер кристаллов гидроксилапатита в композиционном сорбенте от 8 до 18 нм и от 5 до 8 нм соответственно. Величина удельной поверхности композиционного сорбента, определенная с помощью анализатора TriStar II 3020 , равна $96.81 \mathrm{~m}^{2} / \Gamma$ и больше на $85.78 \%$ и $12.85 \%$ по сравнению с бентонитоподобной глиной и гидроксилапатитом соответственно.

Ключевые слова: бентонитоподобная глина, гидроксилапатит, композиционный сорбент, фазовый и гранулометрический состав, морфологические и текстурные характеристики.

\section{Phase and granulometric composition, structural morphological and textural characteristics of the compo- site sorbent}

\author{
Vesentsev A.I. ${ }^{1}$, Dang Minh Thuy ${ }^{1,2}$, Peristaya L.F. ${ }^{1}$, Mihaylyukova M.O. ${ }^{1}$

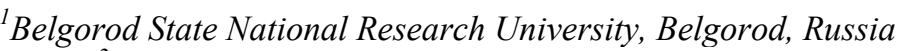 \\ ${ }^{2}$ Vietnam-Russia Tropical Centre. Hanoi, Vietnam
}

The purpose of this article is to determine the phase and granulometric composition, structural, morphological and textural characteristics of composite sorbents based on bentonite-like clay and hydroxylapatite synthesized by chemical precipitation.

X-ray phase analysis and IR spectroscopy revealed the formation of hydroxyaptite crystals in a composite sorbent. The method of the laser diffraction established that the experimental samples consist mainly particles with a size from 0.97 to $125 \mu \mathrm{m}$. The highest proportion of particles of bentonite-like clay is $68.40 \mathrm{wt} \%$, hydroxylapatite $71.77 \mathrm{wt} \%$ and composite sorbent $74.76 \mathrm{wt} \%$ has a size of 1.0 to $10 \mu \mathrm{m}$.

The scanning electron microscopy was established that the bentonite-like clay consists to separate monocrystals of montmorillonite, to accompany minerals and their aggregates. Powders of hydroxylapatite 
consist of particles of elongated form. The surface of the particles composite of bentonite-like clay is covered in the composite sorbent by hydroxylapatite crystals.

The method of transmission electron microscopy established that montmorillonite monocrystal particles have the form of isometric films of 100-300 nm in size with twisting edges. Individual crystals of hydroxylapatite have an elongated form of 35 to $65 \mathrm{~nm}$ in length and 12 to $20 \mathrm{~nm}$ in width, respectively, and in the composite sorbent from 8 to $18 \mathrm{~nm}$ and from 5 to $8 \mathrm{~nm}$, respectively.

The method of low-temperature nitrogen adsorption and desorption has established that bentonitelike clay, hydroxylapatite and composite sorbent have mesoporous structure and contain a small amount of micro- and macropores with an average size of 54.60, 228.18 and $121.93 \AA$, respectively. The specific surface area of the composite sorbent is $96.81 \mathrm{~m}^{2} / \mathrm{g}$, which is higher than the bentonite-like clay and hydroxylapatite by 85.78 and $12.85 \%$, respectively. The obtained results allowed to predict the large sorption capacity of composite materials with heavy metal ions and organic compounds.

Keywords: bentonite-like clay, hydroxylapatite, composite sorbent, phase and granulometric composition, morphological and textural characteristics.

\section{Введение}

Важнейшими проблемами в современном мире являются дефицит пресной воды, низкое качество питьевой воды и необходимость очистки все возрастающих объемов сточных вод от различных поллютантов, среди которых весьма распространенными и опасными являются тяжелые металлы.

В настоящее время для очистки воды применяется метод ионного обмена, который позволяет использовать широкий спектр ионообменных материалов. К физико-химическим методам тонкой очистки воды относится адсорбция. В качестве адсорбентов используют разные природные и синтетические материалы.

Эффективно использование глинистых минералов структурного типа 2:1 с изменяющейся величиной базальных межплоскостных расстояний. В межпакетных полостях подобных минералов могут адсорбироваться молекулы воды и органические вещества, а также положительные ионы радиоактивных и тяжелых металлов. В них может происходить ионный обмен с внешней средой. Указанные глинистые минералы могут разбухать по оси z за счет увеличения пространства между базальными слоями, в котором размещаются адсорбируемые ионы или молекулы [1].

Гидроксилапатит (ГАП), имеющий химическую формулу $\mathrm{Ca}_{10}\left(\mathrm{PO}_{4}\right)_{6}(\mathrm{OH})_{2}$, является основой фосфатных минеральных пород [2]. В последние годы проведены исследования по изучению возможности применения ГАП в качестве сорбента для очистки сточных вод, содержащих тяжелые металлы. Например, Ванг и его коллеги [3] использовали наночастицы ГАП, а Дубовска с коллегами [4] использовали природные и синтетические апатиты для удаления ионов $\mathrm{Cu}^{2+}$ из водных растворов. Авторы $[5,6]$ в своих работах изучали возможность сорбции ионов $\mathrm{Cu}^{2+}, \mathrm{Zn}^{2+}, \mathrm{Cd}^{2+}$, $\mathrm{Pb}^{2+}$ с использованием ГАП и показали, что ГАП обладает высокой сорбционной емкостью ионов этих металлов. Однако адсорбент на основе ГАП имеет общий недостаток, заключающийся в низкой скорости осаждения кристаллов ГАП из водной суспензии.

В настоящее время известно применение композиционных сорбентов, содержащих ГАП, для удаления ионов тяжелых металлов из сточных вод. Например, композиционный гидрогель на основе гидроксилапатита и полиакриламида [7], композит гидроксилапатит - полиуретан [8], композит гидроксилапатит - хитозан [9] и композит гидроксилапатит - магнетит [10] были использованы для удаления ионов токсичных металлов и красителей из водных растворов.

Весьма актуальным является поиск и разработка новых эффективных сорбционных материалов, обеспечивающих понижение концентрации ионов тяжелых металлов в воде до величины, заданной нормативными документами. 
Ранее нами разработан способ получения композиционного сорбента на основе бентонитоподобной глины провинции Лам Донг - Вьетнам (ВТ6) и гидроксилапатита, синтезированного методом химического осаждения [11].

Целью данной работы является определение фазового и гранулометрического состава, структурно-морфологических и текстурных характеристик композиционных сорбентов на основе бентонитоподобной глины и гидроксилапатита (КБГ).

\section{Эксперимент}

Материалы. В качестве исходных сырьевых материалов для получения композиционных сорбентов использовали следующие ингредиенты: гидроксид кальция (ч.д.а) по ГОСТу 9262-77, ортофосфорная кислота (х.ч) по ГОСТу 6552-80 и монтмориллонитсодержащая глина месторождения Там Бо провинции Лам Донг - Вьетнам, которой присвоена маркировка ВТ6. Химический и минералогический состав использованной глины представлены в работе [11].

Фазовый состав, структурно-морфологические и текстурные характеристики экспериментальных сорбентов определяли в Центре коллективного пользования «Технологии и материалы НИУ «БелГУ». Рентгенофазовый анализ (РФА) осуществляли с использованием рентгеновского дифрактометра общего назначения Rigaku Ultima IV (Япония) с детектором D/teX Ultra. Параметры работы генератора: ускоряющее напряжение 40 кВ, ток трубки 40 мА. Параметры съемки: интервал углов $2 \theta=5-85^{0}$, шаг по $2 \theta-0.02^{0}$, скорость регистрации спектров $3^{0} /$ мин.

Морфологические исследования образцов проводили с помощью полевого эмиссионного сканирующего электронного микроскопа (ПЭ-СЭМ) S-4800 (Hitachi, Япония) и просвечивающего (трансмиссионного) электронного микроскопа JEM 1010 (JEOL Ltd., Япония: увеличение до х600.000; разрешение $\delta=3 \AA$; ускоряющее напряжение $U=80$ кB) в Институте наук о материалах Вьетнамской академии наук и технологии (г. Ханой). Образцы для исследования в просвечивающей электронной микроскопии приготовлены в виде суспензии в дистиллированной воде, которую подвергли обработке в ультразвуковой ванне с выходной мощностью 0.12 кВт и частотой 37 кГц в течение 10 мин. В качестве подложки использовали углеродную пленку и медную поддерживающую сеточку диаметром 3 мм.

ИК-спектры получены на инфракрасном спектрофотометре с преобразованием Фурье «IRPrestige-21» (фирма Shimadzu, Япония). Диапазон измерения 4000$400 \mathrm{~cm}^{-1}$. Образец сравнения - KBr. Исследования проведены на кафедре общей химии НИУ «БелГУ».

Изучение гранулометрического состава проводили методом лазерной дифрактометрии на лазерном анализаторе дисперного состава твердых материалов Microtrac S3500 (США) на кафедре общей химии НИУ «БелГУ».

Величина удельной поверхности образцов определена с помощью анализатора удельной площади поверхности TriStar II 3020 методом низкотемпературной адсорбции азота в Центре коллективного пользования «Технологии и материалы НИУ «БелГУ».

\section{Обсуждение результатов}

Фазовый состав экспериментальных сорбентов. Идентификацию фазового состава нативной глины и полученных продуктов проводили на основе анализа рентгеновских порошковых дифрактограмм. На рис. 1 (кривая 1) показано, что в исследуемой глине зафиксировано присутствие монтмориллонита, с основными отраже- 
ниями: $13.485,4.499,2.995,2.129,1.491 \AA$, каолинита 7.212, 4.499, 3.590, $1.423 \AA$ и кварца 4.260, 3.348, 2.459, $1.189 \AA$.

На рис. 1 (кривая 2) представлена рентгеновская порошковая дифрактограмма синтетического ГАП. Указанная дифрактограмма полностью идентична таковой типичного мономинерального гидроксилапатита (PDF карта № 01-074-3709). Другие фазы не зафиксированы.

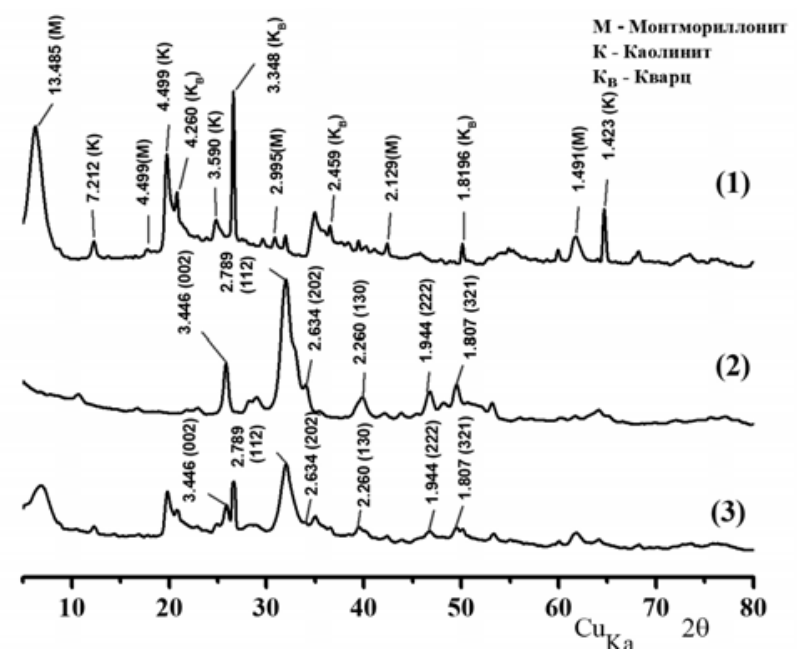

Рис. 1. Рентгеновские порошковые дифрактограммы: 1 - ВТ6; 2 - ГАП; 3 - КБГ

На рис. 1 (кривая 3) приведена порошковая рентгеновская дифрактограмма образца композиционного сорбента КБГ, на которой наблюдаются пики, соответствующие отражениям рентгеновских лучей от семейств миллеровских плоскостей кристаллической решетки гидроксилапатита с величиной межплоскостных расстояний равных $\mathrm{d}_{(002)}=3.446, \mathrm{~d}_{(112)}=2.789, \mathrm{~d}_{(202)}=2.634, \mathrm{~d}_{(130)}=2.26, \mathrm{~d}_{(222)}=1.944, \mathrm{~d}_{(321)}=1.807$ А̊. Появление указанных отражений подтверждает формирование кристаллической структуры ГАП $[12,13]$ в композиционном сорбенте КБГ.

Структурные характеристики экспериментальных сорбентов. На рис. 2 (кривая 1) представлен ИК-спектр бентонитоподобной глины месторождения Там Бо провинции Лам Донг (Вьетнам), на котором присутствуют характерные для монтмориллонита полосы в области валентных и деформационных колебаний структурных групп. Острая и интенсивная полоса с хорошим разрешением около 3619; 3697 и 913 $\mathrm{cm}^{-1}$ в области валентных деформационных колебаний группы X-OH (где X- Al, Si) связана с катионами в октаэдрической координации [14]. Пики, соответствующие максимальным поглощениям около 3419 и $1643 \mathrm{~cm}^{-1}$, принадлежат валентным и деформационным колебаниям воды $[15,16]$. Пики в области $1000-1100 \mathrm{~cm}^{-1}$, а именно, полосы $1032 \mathrm{~cm}^{-1}$ соответствуют валентным колебаниям мостиковых связей $\mathrm{Si}-\mathrm{O}-\mathrm{Si}$ в кристаллической решётке монтмориллонита. Полосы около 462 и $693 \mathrm{~cm}^{-1}$ относятся к деформационным колебаниям угла $\mathrm{Si}-\mathrm{O}-\mathrm{Si}$ [14].

На рис. 2. (кривая 2) присутствуют полосы, характерные для ГАП стехиометрического состава: полоса $(\mathrm{OH})^{-}$при $3570 \mathrm{~cm}^{-1}$; полосы валентных колебаний $\left(\mathrm{PO}_{4}\right)^{3-}$ групп: 1092 (слабое плечо), 1033 и $963 \mathrm{~cm}^{-1}$; полосы деформационных колебаний $\left(\mathrm{PO}_{4}\right)^{3-}$-групп: 604, 566 и $470 \mathrm{~cm}^{-1}$. В спектрах зафиксированы полосы, характерные для колебаний $(\mathrm{OH})^{-}$групп ГАП и карбонатных групп 1420 и $875 \mathrm{~cm}^{-1}[17,18]$, частично замещающих $\left(\mathrm{PO}_{4}\right)^{3-}$, внедренных в структуру ГАП при его синтезе за счет взаимодействия с $\mathrm{CO}_{2}$ воздушной атмосферы. Однако количество этих примесей незначительно, поэтому карбонаты методом рентгенофазового анализа нами не обнаружены. Развитая поверхность ГАП способствует сорбции значительного количества 
воды; валентные колебания сорбционной и кристаллизационной воды характеризуются фоном в области 3500-2900 см ${ }^{-1}$, деформационные колебания H-O-H характеризуются полосой $1671 \mathrm{~cm}^{-1}[19]$.

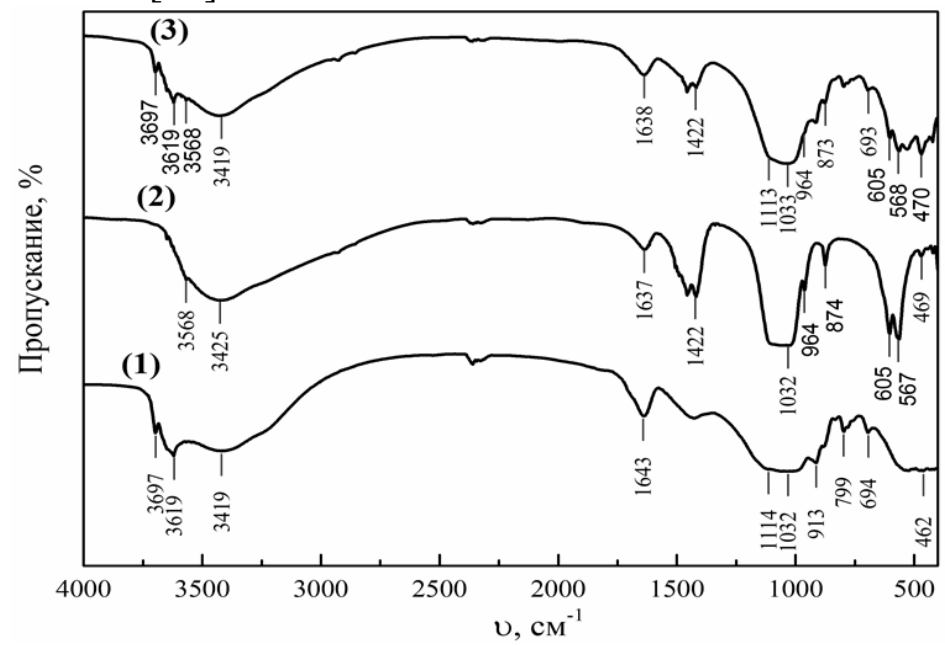

Рис. 2. ИК-спектры: бентонитоподобная глина (1), ГАП (2), КБГ (3).

Из рис. 2 (кривая 3) установлено, что на ИК-спектре образца композиционного сорбента присутствуют полосы, характерные для бентонитоподобной глины и ГАП стехиометрического состава.

Гранулометрический состав экспериментальных сорбентов. Распределение частиц по размеру в образцах ВТ6, ГАП и композиционного сорбента КБГ показано на рис. 3. Установлено, что образцы преимущественно состоят из частиц размером от 0.97 мкм до 125 мкм. Наибольшая доля частиц ВТ6 (68.40 масс.\%), ГАП (71.77 масс.\%) и композиционного сорбента КБГ (74.76 масс.\%) имеет размер от 1.0 до 10 мкм.

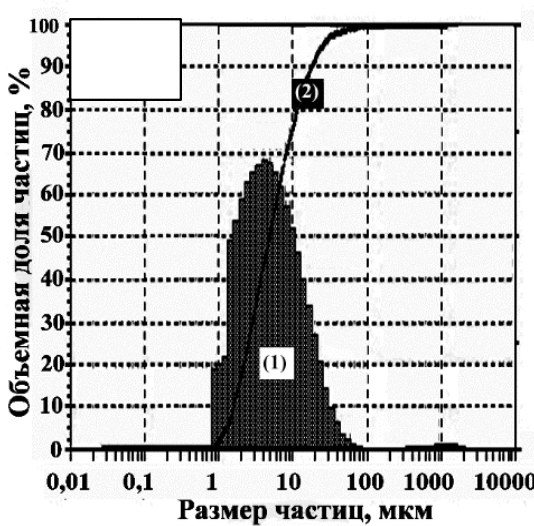

a

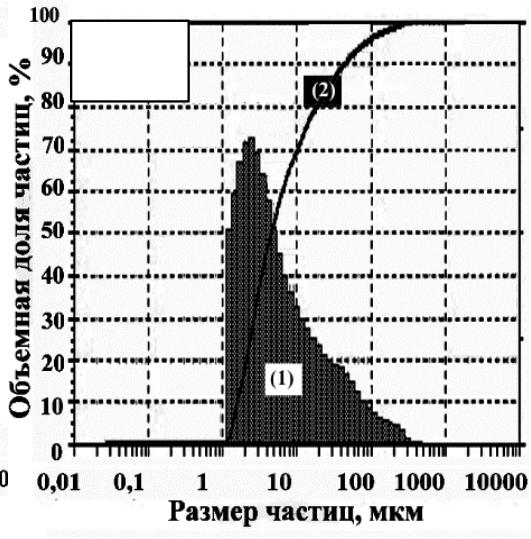

6

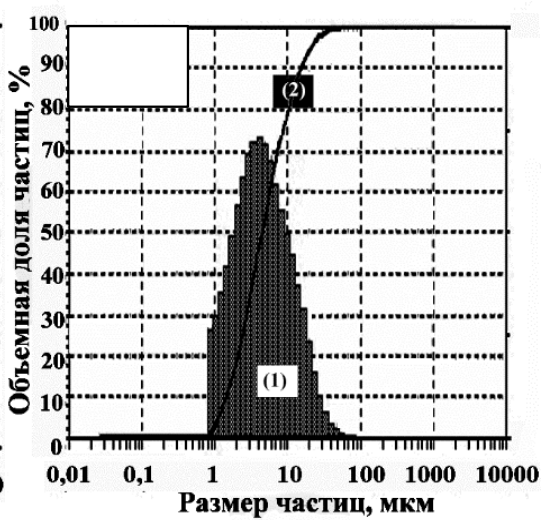

B

Рис. 3. Гистограммы распределения частиц по размеру: а-ВТ6; б-ГАП; в-КБГ.

Интегральная кривая распределения частиц по размерам (1) позволяет отобразить зависимость объемной доли конкретной фракций (масс.\%) от размера частиц. Более наглядное представление о распределении частиц в системе по размерам дает дифференциальная гистограмма распределения (2). По её форме и высоте максимума можно установить, что образцы ВТ6 и КБГ являются монодисперсными системами, и в образце ГАП преобладают более мелкие частицы. Экспериментально доказано, что в образце КБГ по сравнению с нативной глиной и ГАП частиц с размером от 1 до 10 мкм стало больше на 9.2 и 4.2\% соответственно, т.к. в состав компо- 
зиционного сорбента входят как частицы, слагающие глину, так и нанодисперсные кристаллы гидроксилапатита. Основываясь на данных гранулометрического анализа, можно предположить, что удельная поверхность, которая зависит обратно пропорционально размеру частиц, а следовательно и адсорбционная способность композиционного сорбента КБГ увеличатся относительно образцов ВТ6 и ГАП.

Морфологические характеристики частиц экспериментальных сорбентов. Так как метод лазерной дифракции позволяет определить только размер частиц анализируемого материала и не позволяет установить их форму, нами проведено исследование экспериментальных сорбентов методами сканирующей и просвечивающей электронной микроскопии. Морфология частиц бентонитоподобной глины, гидроксилапатита и композиционного материала КБГ, установленная методом сканирующей электронной микроскопии, показана на рис. 4.

Проведенное исследование структурно-морфологических характеристик бентонитоподобной глины позволило установить, что распределение кристаллов монтмориллонита и сопутствующих минералов в глинах неравномерно. На рис. 4а и $4 б$ зафиксированы отдельные листоподобные монокристаллы монтмориллонита. Размер отдельных листоподобных монокристаллов и их агрегатов составляет $0.1-0.6$ и $1-$ 3 мкм соответственно. На рис. 4а и 46 наблюдаются одновременно кристаллы иллита, имеющие чешуйчатую и щепковидную форму [20]. На рис. 4в показано, что порошки ГАП состоят из частиц удлиненной формы длиной от 45 до 75 нм и шириной от 15 до 25 нм. Их форма и размеры стабильны. Из рис. 4г установлено, что поверхность частиц минералов, слагающих бентонитоподобную глину, в образце композиционного материала КБГ покрыта кристаллами гидроксилапатита, имеющими удлиненную форму длиной от 15 до 30 нм и шириной от 10 до 15 нм.

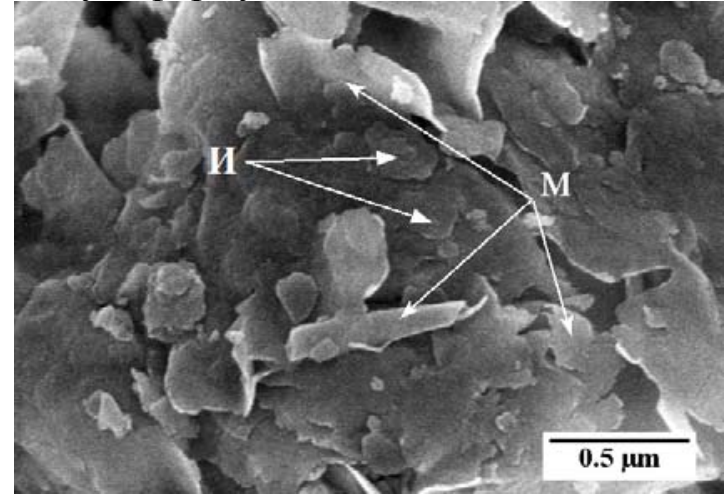

a

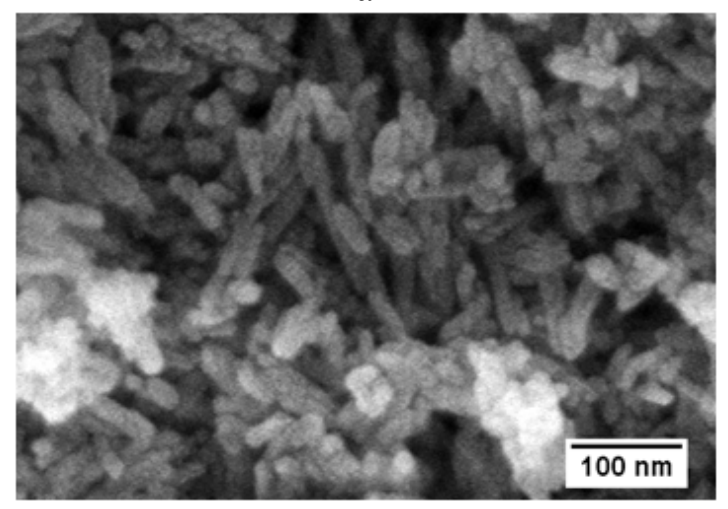

B

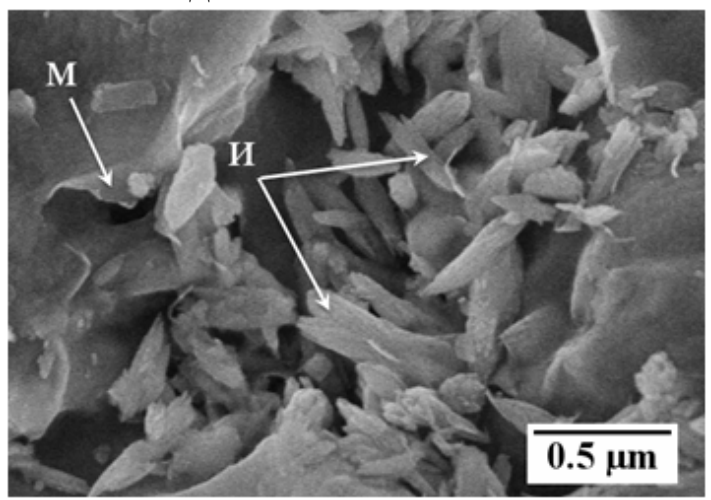

6

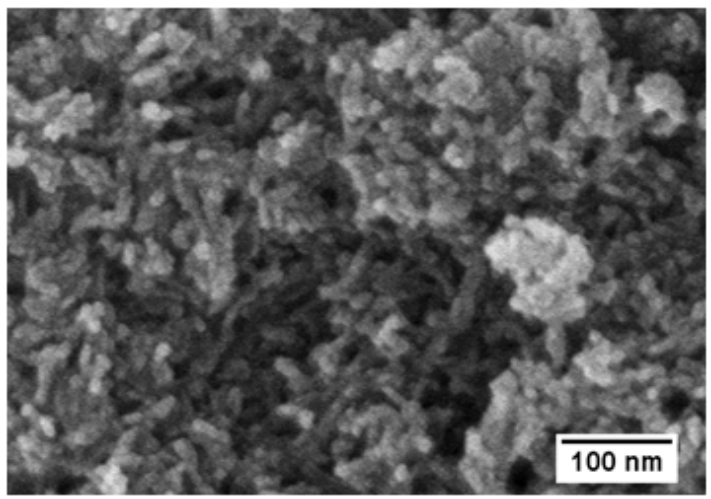

$\Gamma$

Рис. 4. Экспериментальные сорбенты. Сканирующая электронная микроскопия: a, б - Бентонитоподобная глина

(М - монокристаллы монтмориллонита; И - Иллит); в - Гидроксилапатит; г- Композиционный сорбент КБГ. 
К сожалению, фотографии, полученные в сканирующем электронном микроскопе, недостаточно четкие. Это можно объяснить тем, что анализируемые материалы являются диэлектриками, что обуславливает образование электрического заряда под воздействием потока электронов на их поверхности, который практически не удаляется даже у образцов, подвергнутых напылению серебра в вакууме универсального поста. Более полную информацию о морфологических характеристиках монокристаллов монтмориллонита как основного сорбционноактивного минерала исследуемой глины получили методами просвечивающей электронной микроскопии.

Анализируя фотографии, подобные приведенной на рис. 5а, установлено, что кристаллы монтмориллонита представляют собой пленки изометричной формы размером 100 - 300 нм, закручивающиеся по краям, что типично для монтмориллонита. Явление закручивания пленочных монокристаллов вероятно связано с энергетически более выгодным трубчатым состоянием, так как у трубчатых кристаллов силы поверхностного натяжения уравновешены [21]. Также в составе анализируемой глины присутствуют кристаллы каолинита, имеющие вид гексогональных пластин и четкую кристаллографическую огранку. Кварц представлен на рисунке 5а в виде массивных темных кристаллов.

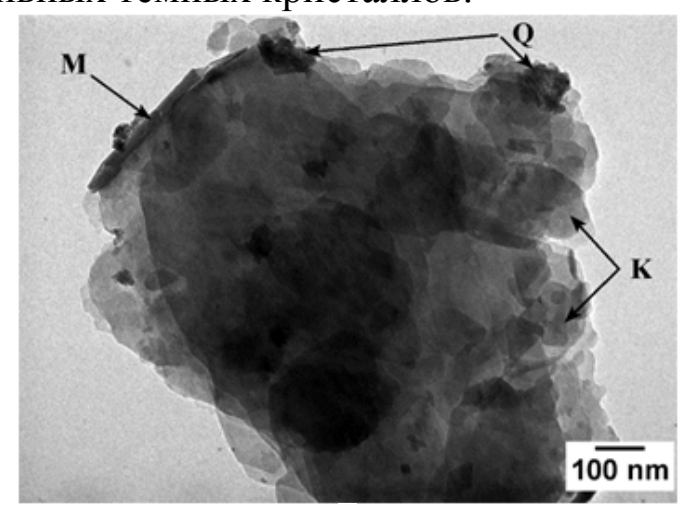

a

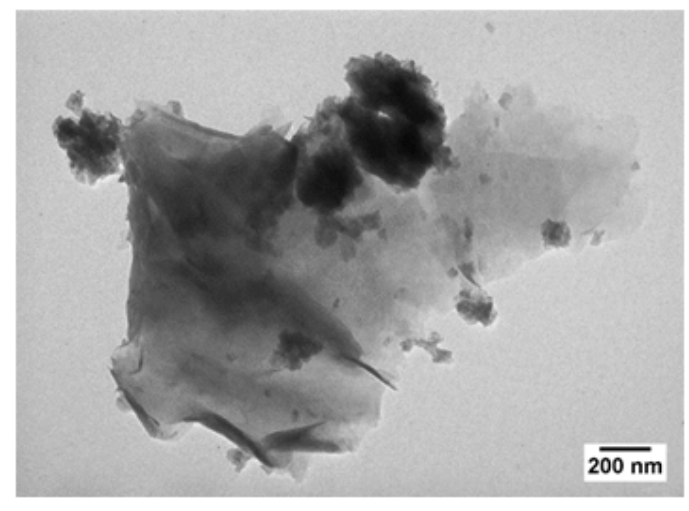

B

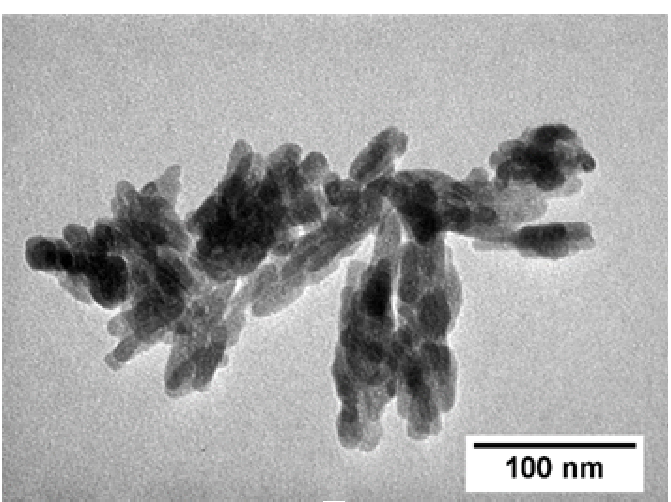

б

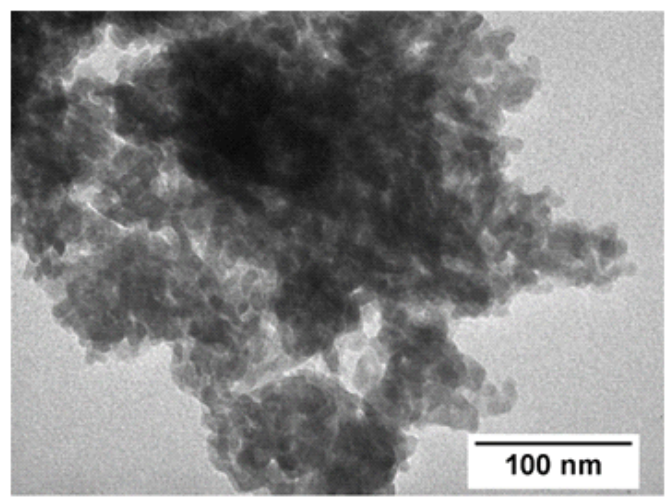

$\Gamma$

Рис. 5. Экспериментальные сорбенты. Просвечивающая электронная микроскопия: а) - Бентонитоподобная глина (М - монтмориллонит; К - каолинит;

Q - кварц); б) - Гидроксилапатит; в, г) - Композиционный сорбент КБГ.

Анализируя фотографии, подобные приведенной на рис. 5б, констатируем, что кристаллы гидроксилапатита имеют удлиненную форму. Эти результаты подтверждают данные, полученные методом сканирующей электронной микроскопии (рис. 4в). Длина и ширина кристаллов гидроксилапатита, определенные методами просвечивающей электронной микроскопии, составляют от 35 до 65 и от 12 до 20 нм соответственно, что соизмеримо с аналогичными параметрами, установленными методами сканирующей электронной микроскопии. Длина и ширина кристаллов ГАП в 
композиционном сорбенте находятся в пределах от 8 до 18 и от 5 до 8 нм соответственно (рис. 5г). Разницу размеров кристаллов гидроксилапатита в ГАП и в композиционном сорбенте можно объяснить тем, что при синтезе монофазового ГАП и композиционного материала КБГ ортофосфорная кислота и гидроксид кальция были использованы в соответствии со стехиометрическими соотношением гидроксилапатита $\mathrm{Ca}: \mathrm{P}=1.62$. Однако при синтезе монофазового ГАП исходные реактивы полностью реагировали между собой, обеспечивая $100 \%$-ный выход заданного продукта, а в условиях получения композиционного материала КБГ часть ортофосфорной кислоты вступила во взаимодействие с минералами, слагающими бентонитоподобную глину, что способствовало уменьшению скорости зарождения и роста кристаллов ГАП.

Благодаря меньшим размерам кристаллов ГАП в композиционном сорбенте, чем у монофазового ГАП, удельная поверхность композиционного сорбента увеличена, что подтверждают нижеизложенные данные (текстурные характеристики).

Текстурные характеристики экспериментальных сорбентов. Изотермы низкотемпературной адсорбции и десорбции азота на бентонитоподобной глине, ГАП и композиционном сорбенте КБГ, приведенные на рис. 6, имеют вид гистерезиса.

По классификации изотерм адсорбции Брунауэра и его соавторов, полученные изотермы относятся к IV типу изотерм, которые соответствуют физической сорбции, присущей мезопористым адсорбентам. Характерный признак изотермы IV типа - наличие петли капиллярно-конденсационного гистерезиса. В зависимости от типа гистерезисных петель, по классификации ИЮПАК бентонитоподобные глины относятся к типу Н3, что характерно для веществ с порами щелевидной формы. Такие петли гистерезиса обусловлены капиллярной конденсацией между двумя параллельными пластинами или листами и характерны для модифицированного монтмориллонита как слоистого силиката структурного типа 2:1 с раздвинутыми плоскопараллельными стенками [22]. Изотермы ГАП относятся к Н3 типу, которые приписываются агрегатам из удлиненных частиц, характеризуются щелевидными порами [23]. Изотермы КБГ также относятся к Н3 типу. Они имеют гибридную гистерезисную петлю бентонитоподобной глины и гидроксилапатита, т.е. в композиционном сорбенте имеются как щелевидные микропоры с параллельными стенками, так и образованные агрегатами из изометричных пластинчатых и удлиненных частиц. Петля гистерезиса на изотерме десорбции всех образцов смыкается при относительном давлении 0.15, что свидетельствует о наличии микропор (в отсутствие микропор петли гистерезиса на всех изотермах в процессе десорбции смыкаются ранее, чем относительное давление достигнет величины 0.3) [24]. На изотермах при $\mathrm{P} / \mathrm{P}_{\text {o }}$ близких к 1, наблюдается резкий подъем сорбционной кривой, указывающий на незначительное наличие в образцах крупных пор. В начальной части изотерм в интервале относительного давления от 0 до 0.45 (ВТ6 и КБГ) и от $0-0.79$ (ГАП) адсорбция характеризуется образованием тонкого слоя сорбированных молекул азота на стенках пор, то есть происходит мономолекулярная адсорбция. Значения относительного давления 0.45 и 0.79 соответствуют началу капиллярной конденсации в наиболее мелких порах. По мере возрастания давления заполняются все более крупные поры, пока при давлении насыщенного пара вся система не окажется заполненной конденсатом, что соответствует случаю полимолекулярной адсорбции.

Таким образом, все исследованные образцы имеют четко выраженную мезопористую структуру и содержат незначительное количество микро- и макропор. По классификации, предложенной М.М. Дубининым и принятой ИЮПАК, размер пор образцов ВТ6, ГАП и КБГ соответствует мезопорам, входящим в диапазон от 30 до $2000 \AA[25]$. 


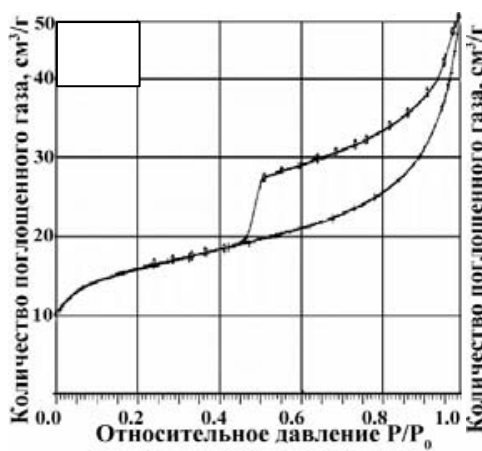

a

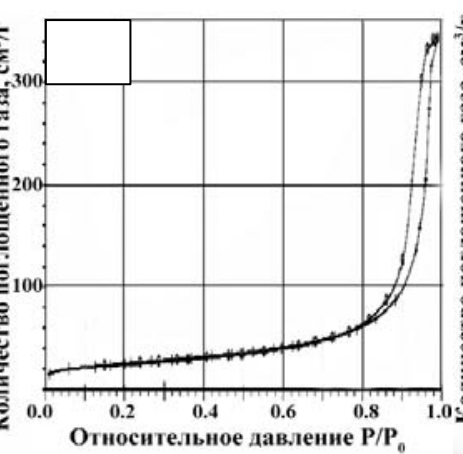

6

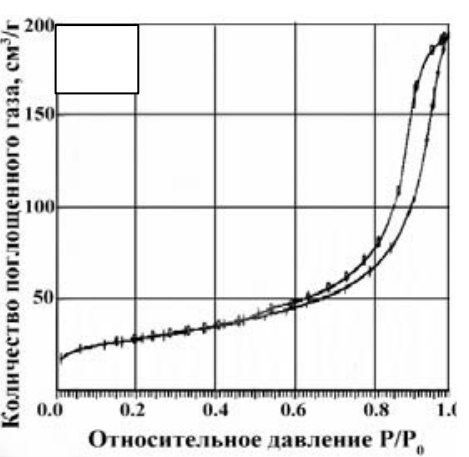

B

Рис. 6. Изотермы низкотемпературной адсорбции и десорбции азота: а) - ВТ6, б) - ГАП, в) - КБГ

Результаты экспериментального определения текстурных характеристик представлены в таблице.

Таблица. Текстурные характеристики экспериментальных сорбентов

\begin{tabular}{|c|c|c|c|c|}
\hline Образец & $\begin{array}{c}\text { Удельная поверхность } \\
\text { по одноточечному ме- } \\
\text { тоду БЭТ, } \mathrm{m}^{2} / \Gamma\end{array}$ & $\begin{array}{c}\text { Удельная поверхность } \\
\text { по пятиточечному ме- } \\
\text { тоду БЭТ, } \mathrm{m}^{2} / \Gamma\end{array}$ & $\begin{array}{c}\text { Удельный } \\
\text { объем пор, } \\
\mathrm{cm}^{3} / \Gamma\end{array}$ & $\begin{array}{c}\text { Средний } \\
\text { размер пор, } \\
\AA\end{array}$ \\
\hline ВТ6 & 51.26 & 52.11 & 0.0711 & 54.60 \\
\hline ГАП & 84.68 & 85.78 & 0.4894 & 228.18 \\
\hline КБГ & 95.39 & 96.81 & 0.2951 & 121.93 \\
\hline
\end{tabular}

Из данных таблицы и рис. 6 установлено, что по мере увеличения размеров пор (ВТ6, КБГ, ГАП составляют 54.6; 121.93; $228.18 \AA$ соответственно) петля гистерезиса сдвигается вправо, приближаясь к оси абсцисс $\mathrm{P} / \mathrm{P}_{0}=1$. Начало конденсации адсорбата наблюдается при относительном давлении паров азота $\mathrm{P} / \mathrm{P}_{0} \approx 0.45 ; 0.45$ и 0.79 соответственно. Ширина гистерезисных петель уменьшается. Максимальное значение адсорбции составляет: 52; 197; $350 \mathrm{~cm}^{3}$ газообразного азота, поглощенного одним граммом адсорбента соответственно.

Из табл. следует, что удельная поверхность композиционного сорбента КБГ больше, чем у бентонитоподобной глины и ГАП на 85.78 и $12.85 \%$ соответственно. Это можно объяснить химическим взаимодействием минералов, входящих в состав бентонитоподобной глины, включая высокодисперсный низкотемпературный тригональный кварц, с ионами $\mathrm{Ca}^{2+}$ и молекулами гидроксида кальция и ортофосфорной кислоты. Взаимодействие ионов $\mathrm{Ca}^{2+}$ и молекул гидроксида кальция с кристаллическими частицами минералов, слагающих глину, сводится к физическим и химическим адсорбциям. В результате хемосорбции ионов $\mathrm{Ca}^{2+}$ и молекул гидроксида кальция минералами бентонитоподобной глины образуются высокодисперсные новообразования с несовершенной кристаллической решеткой типа гидросиликатов, гидроалюминатов, гидроалюмосиликатов кальция, оседающие на поверхности частиц минералов. При взаимодействии ортофосфорной кислоты с глинистыми минералами (монтмориллонитом и каолинитом) происходит полное вымывание катионов $\mathrm{Na}^{+}$, $\mathrm{Mg}^{2+}$ и $\mathrm{Fe}^{3+}$ из межпакетных позиций и частичное вымывание катионов $\mathrm{Al}^{3+}$ из октаэдрических позиций с образованием соответствующих высокодисперсных структурно-несовершенных фосфатов. Подобные соединения обладают собственной высокоразвитой поверхностью[26, 27]. 


\section{Заключение}

Методами рентгенофазового анализа и ИК-спектроскопии зафиксировано образование кристаллов ГАП в композиционном сорбенте. Методом лазерной дифракции установлено, что образцы экспериментальных сорбентов преимущественно состоят из частиц размером от 0.97 мкм до 125 мкм. Наибольшая доля частиц, составляющая для ВТ6 равна 68.40 масс.\%, ГАП - 71.77 масс.\% и композиционного сорбента КБГ - 74.76 масс.\% имеет размер от 1.0 до 10 мкм.

Методом сканирующей электронной микроскопии установлено, что анализируемая бентонитоподобная глина состоит из отдельных листоподобных монокристаллов монтмориллонита, сопутствующих минералов и их агрегатов. Порошки ГАП состоят из частиц удлиненной формы. Поверхность частиц минералов, слагающих бентонитоподобную глину, в композиционном сорбенте КБГ покрыта кристаллами гидроксилапатита.

Методом просвечивающей электронной микроскопии установлено, что частицы монокристаллов монтмориллонита имеют вид изометрических пленок размером 100-300 нм с закручивающимися краями. Отдельные кристаллы ГАП имеют удлиненную форму длиной от 35 до 65 нм и шириной от 12 до 20 нм соответственно, а в композиционном сорбенте от 8 до 18 нм и от 5 до 8 нм соответственно.

Методом низкотемпературной адсорбции и десорбции азота установлено, что по характеру изотерм бентонитоподобная глина, гидроксилапатит и композиционный сорбент имеют мезопористую структуру и содержат незначительное количество микро- и макропор со средним размером 54.60, 228.18 и $121.93 \AA$ соответственно. Удельная поверхность композиционного сорбента КБГ составляет $96.81 \mathrm{~m}^{2} / \Gamma$, что больше по сравнению с бентонитоподобной глиной и гидроксилапатитом на 85.78 и $12.85 \%$ соответственно. Полученные результаты позволяют прогнозировать большую сорбционную емкость разработанных композиционных материалов по отношению как к ионам тяжелых металлов, так и к органическим веществам.

\section{Список литературы}

1. Везенцев А.И., Голдовская Л.Ф., Воловичева Н.А., Королькова С.В. // Сорбиионные и хроматографические прочессы. 2008. T. 8. № 5. C. 807-811

2. Gupta N., Kushwaha A.K., Chattopadhyaya M.C. // Journal of the Taiwan Institute of Chemical Engineers. 2012. Vol. 43. pp. 125-131.

3. Wang Y. J., Chen J. H., Cui Y. X., Wang S. Q., Zhou D.-M. // Journal of Hazardous Materials. 2009. Vol. 162. pp. 1135-1140.

4. Dybowska A., Manning D. A., Collins M. J., Wess T. et al. // Science of the total environment. 2009. Vol. 407. pp. 2953-2965.

5. Corami A., Mignardi S., Ferrini V. // Journal of Hazardous Materials. 2007. Vol. 146. pp. 164-170.

6. Smičiklas I., Onjia A., Raičević S., Janaćković Đ., Mitrić M. // Journal of Hazardous Materials. 2008. Vol. 152. pp. 876-884.
7. Jang S. H., Jeong Y. G., Min B. G., Lyoo W. S., Lee S. C. // Journal of Hazardous Materials. 2008. Vol. 159. pp. 294-299.

8. Jang S. H., Min B. G., Jeong Y. G., Lyoo W. S., Lee S. C. // Journal of Hazardous Materials. 2008. Vol. 152. pp. 1285-1292.

9. Hou H., Zhou R., Wu P., Wu L. // Chemical engineering journal. 2012. Vol. 211. pp. 336342.

10. Dong L., Zhu Z., Qiu Y., Zhao J. // Chemical Engineering Journal. 2010. Vol. 165. pp. 827-834.

11. Везенцев А.И., Данг Минь Тхуи, Перистая Л.Ф. Сборник научных трудов по материалам международной научнопрактической конференции, 30 декабря 2017 г., Тамбов. 2017. Т. 2. С. 30-32

12. Wang Y., Chen N., Wei W., Cui J. et al., Desalination. 2011. Vol. 276. pp. 161-168.

13. Jie W., Yubao L. // European Polymer Journal. 2004, Vol. 40, pp. 509-515. 
14. Zhirong L., Uddin M. A., Zhanxue S. // Spectrochimica Acta Part A: Molecular and Biomolecular Spectroscopy. 2011. Vol. 79. pp. 1013-1016.

15. Тарасевич Ю. И., Овчаренко Ф. Д. Адсорбция на глинистых минералах. Киев. Наукова думка. 1975. 329 с.

16. Tyagi B., Chudasama C.D., Jasra R.V. // Spectrochimica Acta Part A: Molecular and Biomolecular Spectroscopy. 2006. Vol. 64. pp. 273-278.

17. Shahmohammadi M., Jahandideh R., Behnamghader A., Rangie M. // International Journal of Nano Dimension. 2010. Vol. 1. pp. 41-45.

18. Thamaraiselvi T. V., Prabakaran K., Rajeswari S. // Trends Biomater Artif Organs. 2006. Vol. 19. pp. 81-83.

19. Захаров Н.А., Сенцов М.Ю.// Сорбриионные и хроматографические прочессы. 2011. T. 11. № 2. C. 177-184.

20. Umar M., Friis H., Khan A. S., Kassi A. M., Kasi A. K. // Journal of Asian Earth Sciences. 2011. Vol. 40. pp. 622-635.

\section{References}

1. Vesentsev A.I., Goldovskaya L.F., Volovicheva N.A., Korol'kova S.V. ,Sorbtsionnye $i$ khromatograficheskie protsessy, 2008, Vol. 8, No. 5, pp. 807-811.

2. Gupta N., Kushwaha A.K., Chattopadhyaya M.C., Journal of the Taiwan Institute of Chemical Engineers, 2012, Vol. 43, pp. 125-131. DOI: 10.1016/j.jtice.2011.07.009

3. Wang Y.-J., Chen J.H., Cui Y.X., Wang S.Q., Zhou D.M., Journal of Hazardous Materials, 2009, Vol. 162, pp. 1135-1140. DOI: 10.1016/j.jhazmat.2008.06.001

4. Dybowska A., Manning D. A., Collins M. J., Wess T. et al., Science of the total environment, 2009, Vol. 407, pp. 2953-2965. DOI: 10.1016/j.scitotenv.2008.12.053

5. Corami A., Mignardi S., Ferrini V., Journal of Hazardous Materials, 2007, Vol. 146, pp. 164-170. DOI: 10.1016/j.jhazmat.2006.12.003

6. Smičiklas I., Onjia A., Raičević S., Janaćković Đ., Mitrić M., Journal of Hazardous Materials, 2008, Vol. 152, pp. 876-884. DOI: 10.1016/j.jhazmat.2007.07.056

7. Jang S.H., Jeong Y.G., Min B.G., Lyoo W.S. et al., Journal of Hazardous Materials, 2008, Vol. 159, pp. 294-299. DOI: 10.1016/j.jhazmat.2008.02.018
21. Bui Quang $\mathrm{Cu}$, Nguen Hoai Chao, Vesentsev A. I., Bukhanov V. D. et al. Research result. 2016. Vol. 2. pp. 63-74.

22. Карнаухов А. П. Адсорбция. Текстура дисперсных и пористых материалов. Новосибирск. Наука. 1999. 470 с.

23. E1 Shafei G.M., Philip C.A., Moussa N.A. // Journal of colloid and interface science. 2004. Vol. 277. pp. 410-416.

24. Вячеславов А.С., Померанцева Е.А. Методическая разработка: Измерение площади поверхности и пористости методом капиллярной конденсации азота. М. 2006. 55 c.

25. Дубинин М. М. Пористая структура и адсорбционные свойства активных углей. М. $1965.70 \mathrm{c}$.

26. Арипов Э. А. Природные минеральные сорбенты, их активирование и модифицирование. "ФАН" УзССР. 1970. 240 с.

27. Комаров В.С., Ратько А.И. Адсорбенты: получение, структура, свойства. Минск. Беларус.наука. 2009. 256 с.

8. Jang S.H., Min B.G., Jeong Y.G., Lyoo W.S. et al., Journal of Hazardous Materials, 2008, Vol. 152, pp. 1285-1292. DOI: 10.1016/j.jhazmat.2007.08.003

9. Hou H., Zhou R., Wu P., Wu L., Chemical engineering journal, 2012, Vol. 211, pp. 336342. DOI: 10.1016/j.cej.2012.09.100

10. Dong L., Zhu Z., Qiu Y., Zhao J., Chemical Engineering Journal, 2010, Vol. 165, pp. 827-834. DOI: 10.1016/j.cej.2010.10.027

11. Vesentsev A. I., Dang Minh Thuy, Peristaya L.F., Collection of scientific papers on the materials of the international scientific-practical conference, December 30, 2017, Tambov, 2017, Vol. 2, pp. 30-32

12. Wang Y., Chen N., Wei W., Cui J., Wei Z., Desalination, 2011, Vol. 276, pp. 161-168. DOI: $10.1016 /$ j.desal.2011.03.033

13. Jie W., Yubao L., European Polymer Journal, 2004, Vol. 40, pp. 509-515. DOI: 10.1016/j.eurpolymj.2003.10.028

14. Zhirong L., Uddin M. A., Zhanxue S., Spectrochimica Acta Part A: Molecular and Biomolecular Spectroscopy, 2011, Vol. 79, pp. 1013-1016. DOI: 10.1016/j.saa.2011.04.013

15. Tarasevich U.I., Ovcharenko F.D. Adsorption on clay minerals.,Kiev, Naukova Dumka, $1975,329 \mathrm{p}$. 
16. Tyagi B., Chudasama C.D., Jasra R.V., Spectrochimica Acta Part A: Molecular and Biomolecular Spectroscopy, 2006, Vol. 64, pp. 273-278. DOI: 10.1016/j.saa.2005.07.018

17. Shahmohammadi M., Jahandideh R., Behnamghader A., Rangie M., International Journal of Nano Dimension, 2010, Vol. 1, pp. 41-45. DOI: 10.7508/IJND.2010.0X.004

18. Thamaraiselvi T. V., Prabakaran K., Rajeswari S., Trends Biomater Artif Organs, 2006. Vol. 19. pp. 81-83.

19. Zakharov N.A., Sentsov M.Y., Sorbtsionnye $i$ khromatograficheskie protsessy, 2011, Vol. 11, No 2, pp. 177-184.

20. Umar M., Friis H., Khan A. S., Kassi A. M. et al., Journal of Asian Earth Sciences, 2011, Vol. 40, pp. 622-635. DOI: 10.1016/j.jseaes.2010.10.014

21. Bui Quang $\mathrm{Cu}$, Nguen Hoai Chao, Vesentsev A.I., Bukhanov V.D. et al., Research result, 2016, Vol. 2, pp. 63-74. DOI: 10.18413/2500$235 \mathrm{X}-2016-2-3-63-74$

Везенцев Александр Иванович - д.т.н., профессор, зав, кафедрой общей химии Института инженерных технологий и естественных наук, ФГАОУ ВО «Белгородский государственный национальный исследовательский университет», НИУ «БелГУ», Белгород

Перистая Лидия Федотовна - доцент кафедры общей химии Института инженерных технологий и естественных наук, ФГАОУ ВО «Белгородский государственный национальный исследовательский университет», НИУ «БелГУ», Белгород

Данг Минь Тхуи - аспирант 3 года обучения, ФГАОУ ВО «Белгородский государственный национальный исследовательский университет», НИУ «БелГУ», Бедгород.

Михайлюкова Мария Олеговна - аспирант 3 года обучения, ФГАОУ ВО «Белгородский государственный национальный исследовательский университет», НИУ «БелГУ», Белгород.
22. Karnaukhov A.P., Adsorbtsiya. Tekstura dispersnykh I poristykh materialov, Novosibirsk, Nauka Publ, 1999, 470 p.

23. El Shafei G.M., Philip C.A., Moussa N.A., Journal of colloid and interface science, 2004, Vol. 277, pp. 410-416. DOI: 10.1016/j.jcis.2004.05.002

24. Vyacheslavov A. S., Pomerantseva E. A., Metodicheskaya razrabotka: Izmerenie ploshchadi poverkhnosti i poristosti metodom kapillyarnoi kondensatsii azota, M., 2006, 55 p.

25. Dubinin M. M., Poristaya struktura I adsorbtsionnye svoistva akivnykh uglei, M., 1965, $70 \mathrm{p}$.

26. Aripov E. A., Prirodnye mineral'nye sorbenty, ikh aktivirovanie i modifitsirovanie, "FAN" UzSSR, 1970, 240 p.

27. Komarov V. S., Rat'ko A. I., Adsorbenty: poluchenie, struktura, svoistva, Minsk, Belarus.nauka Publ, 2009, 256 p.

Vezentsev Aleksandr I. - doctor of technical sciences, professor, head of department of the general chemistry of Institute of engineering technologies and natural sciences, Federal State Autonomous Educational Institution of Higher Education «Belgorod National Research University», Belgorod., E-mail: vesentsev@bsu.edu.ru

Peristaya Lidiya F. - assistant professor of of department of the general chemistry of Institute of engineering technologies and natural sciences, Federal State Autonomous Educational Institution of Higher Education «Belgorod National Research University», Belgorod.

Dang Minh Thuy - PhD student of the $3^{\text {sd }}$ year, Federal State Autonomous Educational Institution of Higher Education «Belgorod National Research University», Belgorod

Mikhailyukova Mariya O. - PhD student of the $3^{\text {sd }}$ year, Federal State Autonomous Educational Institution of Higher Education «Belgorod National Research University», Belgorod. 